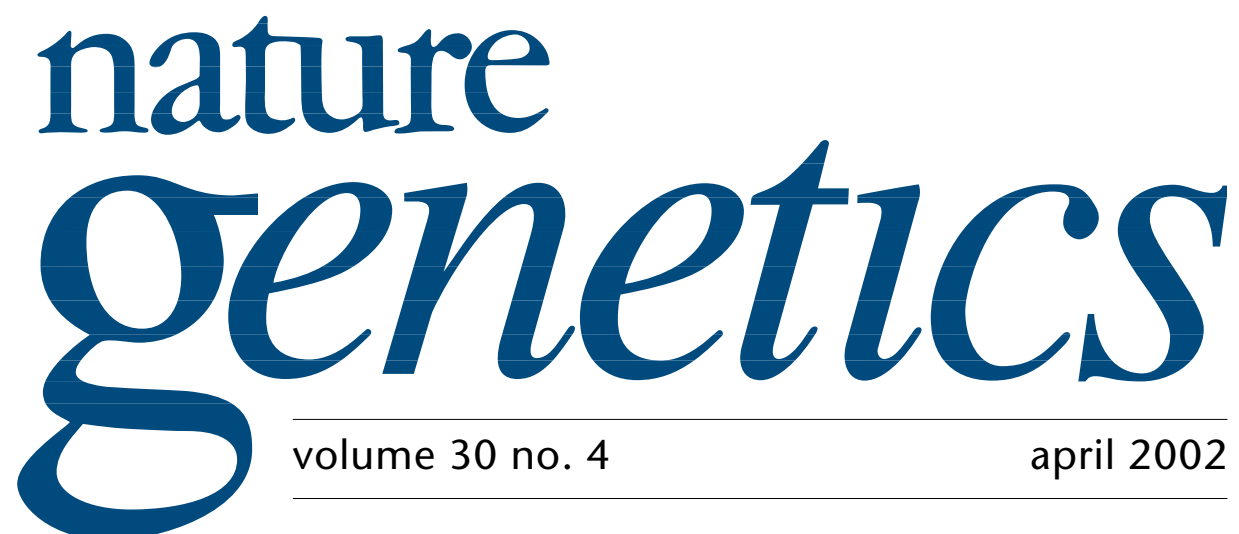

\title{
Wag the dogma
}

In a recent News \& Views article in Nature Genetics ${ }^{1}$, David Goldstein offered that "The natural world is not famous for making life easy for human geneticists." A fair statement, although most would probably agree that at least the hard-won intellectual foundations of the field are secure. What a surprise, then, to pick up February's issue of Harper's Magazine, and to read that the entire enterprise has been revealed to be a sham.

In a long essay entitled "Unraveling The DNA Myth", Barry Commoner declares that the fruits of the Human Genome Project, along with other findings of modern genetics, have undermined everything geneticists thought to be true about their subject. Francis Crick's central dogma is dead, and the creaky, DNA-based edifice of genetics and biotechnology is baseless. The central dogma, according to Commoner, assumes that "an organism's genome...should fully account for its characteristic assemblage of inherited traits." He continues, arguing that "The premise, unhappily, is false. Tested between 1990 and 2001 in one of the largest and most highly publicized scientific undertakings of our time, the Human Genome Project, the theory collapsed under the weight of fact. There are far too few human genes to account for the complexity of our inherited traits." What's more, "the downfall of the central dogma... also destroyed the scientific foundation of genetic engineering."

That would certainly be newsworthy, and yet, as Commoner points out, "Scientists and journalists somehow failed to notice." One explanation, which he favors, is a wag-the-dog-like scenario, in which, in order to deflect attention from the fact that billions of dollars are being poured into a field that is on shaky ground, scientists stifle dissent and pretend that evidence of biological complexity has not put the lie to the central dogma.

An alternative explanation for the indifference that has greeted the downfall of the central dogma is that, in the strictest sense, it isn't true. Crick's original proposal ${ }^{2}$ had nothing to do with the relationship between an organism's genome and its inherited traits; it simply stated that information flow in the cell goes from nucleic acids to proteins. The obvious exception to this statement is the prion hypothesis, whose father, Stanley Prusiner, was awarded a Nobel Prize, a rather odd way for the scientific community to express its disapproval of heretical ideas.

In another sense, there is broad agreement on the points that Commoner raises. It has been widely held, for at least 25 years $^{3}$, that biological complexity probably has more to do with complex gene regulation than with gene number. And even if one takes Commoner's broader view of the central dogma, it is hard to see what the fuss is about. The often obscure path from genotype to phenotype is, of course, 
1. Goldstein, D.B. Nature Genet. 29, 109-111 (2001).

2. Crick, F.H.C. Symp. Soc. Exp. Biol. 12, 138-163 (1957).

3. Jacob, F. Science 196, 1161-1166 (1977)

4. Judson, H.F. The Eighth Day of Creation 608 (Cold Spring Harbor Laboratory Press, Cold Spring Harbor, 1996). dependent on the protein-protein interactions that underlie alternative splicing, post-translational modification, gene silencing and epigenetic regulation, in addition to a whole host of environmental factors. Commoner seems to be arguing that geneticists have documented this complexity, but have not taken it to heart: "Divergent evidence is duly reported and, often enough, generates intense research, but its clash with the governing theory is almost never noted."

But what can this mean? That geneticists really think their subject can be reduced to the simplified shorthand they sometimes employ in public pronouncements? Surely not. That because the Human Genome Project has been subject to hype, there is no there there? Can it really have escaped Commoner's notice that the availability of a complete genome sequence, or even a partial one, is a great boon to the study of the complexity he insists is being swept under the rug?

Lest this be taken as a dismissal of all criticism, it is important to add that the relationship between genetics and biotechnology deserves more rigorous review (see page 355). Finally, the Harper's article should prompt us to heed the words of Horace Freeland Judson": "Less is not more....Oversimplification creates confusion that no reader can comprehend: fuller explanation will bring enlightenment. More can simplify." Bearing this in mind, geneticists need to do a better job of conveying the fact that biology is complicated, and that the human genome sequence has not made understanding it easy_-just a little less hard.

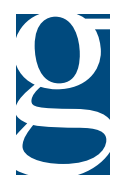

\section{Ten years on}

It is ten years since the launch of Nature Genetics. As explained in the inaugural issue, the journal set out to publish studies that explore the link between genome structure and human disease, the genetics of other organisms, reports on new technologies, and the application of research to genetic therapies. It was also argued that genetic research could provide insights into general biology and ventured that genetics might serve to answer some of the grander questions of biology. It was recognized that genetic research raises important social issues, the discussion of which would find a forum in the journal.

Whereas many of the challenges of 1992 remain just as relevant today, a perusal of the papers in the first issue of Nature Genetics attest to the extraordinary pace of genetic research. Ten years ago, Francis Collins wrote that positional cloning was "genetics in its purest form, unadulterated by any influences of biochemistry, cell biology or physiology". At that time, the genetic etiology of 105 diseases had been described; today there are at least 1,788. In the same issue, Bert Vogelstein and colleagues defined the p53 consensus binding sequence and Craig Venter and colleagues published 106 kilobases of complete human genome sequence and stated, "these results indicate that large parts of the genome can be sequenced using a shotgun approach followed by direct sequencing to fill in the gaps".

To provide a historical record of the past ten years of research, Nature Genetics is pleased to announce the publication, later this year, of a volume of reviews. These will chronicle the development of different areas of genetic research, assess the current state of the field, and highlight challenges of the future. In the meantime, Nature Genetics remains committed to serving the genetic community by providing researchers with "a vehicle for the publication of important research". What will be considered important in the next decade? To some extent, more of the same, although supplemented by insights from even more ambitious undertakings in genomics: gene-gene interactions, genetic contributions to complex disease, and systems biology. Grand questions, indeed.

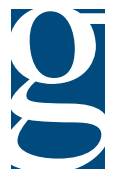

